\title{
Noble metal (Pd, Ru, Rh, Pt, Au, Ag) doped graphene hybrids for electrocatalysis
}

\author{
Marcella Giovanni, ${ }^{a}$ Hwee Ling Poh, ${ }^{a}$ Adriano Ambrosi, ${ }^{a}$ Guanjia Zhao,${ }^{a}$ Zdeněk Sofer, ${ }^{b}$ Filip Šaněk, ${ }^{b}$ \\ Bahareh Khezri, ${ }^{a}$ Richard D. Webster ${ }^{a}$ and Martin Pumera ${ }^{* a}$ \\ Received (in $X X X, X X X)$ Xth $X X X X X X X X X 20 X X$, Accepted Xth $X X X X X X X X X 20 X X$ \\ DOI: $10.1039 / \mathrm{b} 000000 \mathrm{x}$
}

Metal decorated graphene materials are highly important for catalysis. In this work, noble metal doped-graphene hybrids were prepared by a simple and scalable method. The thermal reductions of metal doped-graphite oxide precursors were carried out in nitrogen and hydrogen atmospheres and the effects of these atmospheres as well as the metal components on the characteristics and catalytic capabilities of the hybrid materials were studied. The hybrids exfoliated in nitrogen atmosphere contained a higher amount of oxygen-containing groups and lower density of defects on their surfaces than hybrids exfoliated in hydrogen atmosphere. The metals significantly affected the electrochemical behavior and catalysis of compounds that are important in energy production and storage and in electrochemical sensing. Research in the field of energy storage and production, electrochemical sensing and biosensing as well as biomedical devices can take advantage of the properties and catalytic capabilities of the metal doped graphene hybrids.

\section{Introduction}

The growing needs of developing new sensing methods and energy production systems have made it necessary to find and utilize materials that are able to mediate and enhance the related processes, including reduction and oxidation reactions of the compounds of interest.

Recent research has paid tremendous attention toward graphene due to its unique electrochemical, optical and mechanical properties as well as high surface area and electrical conductivity. ${ }^{1}$ Energy production and storage, ${ }^{2}$ photovoltaics, ${ }^{3}$ catalysis, ${ }^{4}$ electrochemical sensing ${ }^{5}$ and biosensing ${ }^{6,7}$ are only a few out of many potential applications that are brought forward by exploiting the two dimensional, monolayer, $\mathrm{sp}^{2}$-bonded carbon network in a honeycomb lattice of graphene. However, pristine graphene which is free from defects is not commonly used in electrochemical research because of the difficulty of its massproduction. One route to graphene mass-production involves the oxidation of graphite to graphite oxide which is subsequently exfoliated by using chemical, electrochemical or thermal reduction processes. This leads to a type of material named chemically modified graphene (CMG) which comprises graphitic materials with functional groups covalently bound to the surface of the individual layer of the material. ${ }^{8}$ In particular, thermally reduced graphene oxide presents prospective functions in energy storage,

${ }^{a}$ Division of Chemistry and Biological Chemistry, School of Physical and Mathematical Sciences, Nanyang Technological University, 21 Nanyang Link, Singapore 637371.Web: pumera@ntu.edu.sg

${ }^{b}$ Institute of Chemical Technology, Department of Inorganic Chemistry, Techniká 5, 16628 Prague 6, Czech Republic sensing and catalysis because of its fast heterogeneous electron transfer. ${ }^{9}$ Metal nanoparticles also have unique physical and chemical properties which differ from the respective bulk materials. ${ }^{10}$ They have served as platforms to immobilize biomolecules, as labels in bioassays and as catalysts in electrochemical reactions. ${ }^{11}$

Recently, several works on decorating graphene with metal nanoparticles have been reported. ${ }^{12-15}$ This hybrid material shows promising capabilities to be implemented in catalysis and sensing applications. ${ }^{16}$ Several approaches for synthesizing the hybrids include the electrochemical reduction of the metal ions using graphene flakes from graphene oxide, ${ }^{15}$ using external power sources such as microwaves ${ }^{14}$ and the chemical reduction of the metal salts in the presence of reducing agents. ${ }^{13}$ An effort to decorate graphene grown by chemical vapor deposition (CVD) through electroless deposition employed other metals with lower reduction potentials as the substrate and reducing agent. $^{12}$

In the present work, the hybrids between graphene and noble metal nanoparticles, namely palladium (G-Pd), ruthenium (G-Ru), rhodium (G-Rh), platinum (G-Pt), gold (G-Au) and silver (G-Ag) which underwent thermal exfoliation in nitrogen $\left(\mathrm{G}-\mathrm{M} / \mathrm{N}_{2}\right)$ or hydrogen $\left(\mathrm{G}-\mathrm{M} / \mathrm{H}_{2}\right.$, where $\mathrm{M}$ refers to the metals: $\mathrm{Pd}, \mathrm{Ru}, \mathrm{Rh}, \mathrm{Pt}, \mathrm{Au}$ or $\mathrm{Ag}$ ) atmosphere were prepared by a simple and scalable method. The effects of the exfoliation atmospheres as well as the presence of metals on the characteristics and electrocatalytic activities of the materials are studied. The metals used here possess electrocatalytic activities, for example, platinum for oxygen reduction reactions. ${ }^{17}$ These hybrid materials exhibited unique electrochemical properties when compared with 
the undecorated graphene materials. They also offer wide possibilities to be employed in sensing and energy production systems.

\section{Experimental method}

\section{Materials}

Phosphate buffer powder $(0.1 \mathrm{M})$, potassium hexacyanoferrate(II) trihydrate, potassium hexacyanoferrate(III) and potassium hydroxide were obtained from Sigma-Aldrich. Hydrogen peroxide $(27 \% \mathrm{w} / \mathrm{w})$ and hydrazine monohydrate $(99 \%$ w/w) were obtained from Alfa Aesar. $N, N^{\prime}$-Dimethylformamide (GC grade) was purchased from Merck. Phosphate buffer solution (50 mM, pH 7.2) and potassium hydroxide solution (2 M, $\mathrm{pH}$ 13.85) were prepared in Milli-Q water. Solutions of potassium hexacyanoferrate(II) and potassium hexacyanoferrate(III) (10 mM, 1: 1 molar ratio), hydrogen peroxide $(10 \mathrm{mM})$ and hydrazine $(10 \mathrm{mM})$ were prepared in $50 \mathrm{mM}$ phosphate buffer. These reagents were used as received without further purification. Glassy carbon electrodes (GCEs), the $\mathrm{Ag} / \mathrm{AgCl}$ reference electrode and the platinum disc electrode were purchased from $\mathrm{CH}$ Instruments, USA.

\section{Apparatus}

Scanning electron microscopy (SEM) images were obtained by using Jeol 7600F SEM (Jeol, Japan) operating at $2 \mathrm{kV}$ in GB high mode.

Energy-dispersive $X$-ray spectroscopy ( $E D X)$ was recorded on a Jeol $7600 \mathrm{~F}$ (Jeol, Japan) at $15 \mathrm{kV}$.

$X$-ray photoelectron spectroscopy (XPS) was performed using a Phoibos 100 spectrometer and a monochromatic Mg X-ray radiation source (SPECS, Germany). Survey (wide scan) spectra and high-resolution spectra of $\mathrm{C} 1 \mathrm{~s}$ and the metal contained within each sample were recorded. $\mathrm{C} / \mathrm{O}$ ratios were evaluated from the wide scan spectra by using relative sensitivity factors. The samples for SEM, EDX and XPS measurements were prepared by coating carbon conductive tape with a uniform layer of the materials studied.

Inductively coupled plasma-mass spectrometry (ICP-MS) was recorded using an Agilent 7700x ICP-mass spectrometer. Each sample was sonicated 3 times, 30 minutes each time, prior to acid digestion on a Mars CEM system with concentrated nitric acid.

Raman spectroscopy was measured on a confocal microRaman LabRam HR spectrometer (Horiba Scientific, Japan) in backscattering geometry, with excitation from a $514.5 \mathrm{~nm}$ argonion laser beam and a $100 \times$ objective mounted on an optical microscope (Olympus). The instrument was calibrated using an internal silicon reference at $520 \mathrm{~cm}^{-1}$ and the peak position resolution was less than $1 \mathrm{~cm}^{-1}$. To record the Raman spectra, the dispersion of samples was dropped on glass slip and after drying compressed with another clean glass slip to obtain a compact and uniform layer of material.

Cyclic voltammetry experiments were performed on a $\mu$ AutolabIII electrochemical analyzer (Eco Chemie, The Netherlands) controlled by General Purpose Electrochemical System (GPES) software version 4.9 (Eco Chemie). A three-electrode configuration was used to conduct the experiments in a $5 \mathrm{~mL}$ electrochemical cell. An $\mathrm{Ag} / \mathrm{AgCl}$ electrode was employed as the reference electrode and a $\mathrm{Pt}$ disc was used as the auxiliary electrode. All voltammetric experiments were carried out at room temperature $\left(22^{\circ} \mathrm{C}\right)$. All the potentials are stated $v s$. $\mathrm{Ag} / \mathrm{AgCl}$.

\section{Procedures}

The preparation of graphite oxide followed a method described by Hofmann. ${ }^{18}$ Graphite $(5 \mathrm{~g})$ was added into a mixture of sulfuric acid $(98 \%, 87.5 \mathrm{~mL})$ and nitric acid $(68 \%, 27 \mathrm{~mL})$. Potassium chlorate (55 g) was slowly added into the mixture while cooling the resultant mixture in an ice bath. The reaction mixture was then stirred for 96 hours at room temperature. After the reaction reached completion, the mixture was poured into $3 \mathrm{~L}$ of deionized water and decanted. The resulting graphite oxide was then redispersed in 5\% hydrochloric acid solution and repeatedly centrifuged to remove chloride and sulphate ions. Graphite oxide slurry was then dried in a vacuum oven at $60^{\circ} \mathrm{C}$ for 48 hours before use.

Graphite oxide $(100 \mathrm{mg})$ was redispersed in water $(10 \mathrm{~mL})$ containing the metal ion of interest in the form of its salt $(1 \mathrm{mg})$ by ultrasonication; the salts were palladium(II) chloride, ruthenium(III) chloride, rhodium(III) chloride, ammonium hexachloroplatinate(IV), gold(III) chloride and silver nitrate. The suspension was consequently dried in a vacuum oven at $60{ }^{\circ} \mathrm{C}$ for 48 hours to yield the metal doped-graphite oxide precursor powders. The thermal exfoliation of the dry precursor was carried out at $1000{ }^{\circ} \mathrm{C}$ for 12 minutes, by placing the precursor inside a porous quartz glass capsule connected to a magnetic manipulator in a vacuum tight quartz reactor with controlled atmosphere. This system provided a temperature gradient of over $1000{ }^{\circ} \mathrm{C} \mathrm{min}^{-1}$. The sample was then flushed repeatedly with pure nitrogen and subsequently inserted into a preheated reactor in nitrogen (99.9999\% purity) or hydrogen (99.9999\% purity) atmosphere (pressure: $1 \mathrm{~atm})$ to give the noble metal doped graphene hybrid material. The flow of the gases was $1000 \mathrm{~mL}$ $\min ^{-1}$, resulting in the removal of the by-products of the reactions.

To immobilize the material on the glassy carbon working electrode surface, the dispersion of the noble metal doped graphene hybrid $\left(0.5 \mathrm{mg} \mathrm{mL} \mathrm{mL}^{-1}\right)$ in $N, N^{\prime}$-dimethylformamide (DMF) was first ultrasonicated for 60 seconds. $3 \mu \mathrm{L}$ of the resulting suspension were then deposited onto the glassy carbon electrode (GCE) surface in $1 \mu \mathrm{L}$ steps and allowed to dry, resulting in a film of randomly distributed materials on the electrode surface.

Cyclic voltammetry measurements were recorded at a scan rate of $100 \mathrm{mV} \mathrm{s}^{-1}$ in phosphate buffer solutions $(50 \mathrm{mM}, \mathrm{pH} 7.2)$ only with phosphate buffer solution as the supporting electrolyte for $\mathrm{K}_{4}\left[\mathrm{Fe}(\mathrm{CN})_{6}\right] / \mathrm{K}_{3}\left[\mathrm{Fe}(\mathrm{CN})_{6}\right](10 \mathrm{mM}, 1: 1$ molar ratio), hydrogen peroxide $(10 \mathrm{mM})$ and hydrazine $(10 \mathrm{mM})$ or at $10 \mathrm{mV} \mathrm{s}^{-1}$ in potassium hydroxide solution $(2 \mathrm{M}, \mathrm{pH} 13.85)$ saturated with air for the oxygen reduction reaction. The GCE surface was renewed by polishing it with alumina slurry.

The heterogeneous electron transfer rates $\left(k^{0}{ }_{\text {obs }}\right)$ were calculated by using the method described by Nicholson, ${ }^{19}$ which relates the peak-to-peak separation $\left(\Delta E_{\mathrm{p}}\right)$ to a dimensionless parameter $\psi$ and subsequently to $k^{0}{ }_{\text {obs }}$. The value of the diffusion coefficient $D=7.35 \times 10^{-6} \mathrm{~cm}^{2} \mathrm{~s}^{-1}$ for $\left[\mathrm{Fe}(\mathrm{CN})_{6}\right]^{3-/ 4-}$ was used 
throughout the calculations..$^{20}$ The electrochemical rate constants are in general influenced by nature of electrolyte, its concentration or specific ion adsorption. ${ }^{24}$ For this reason we state observed heterogeneous transfer rate constants and not the true HET rate constants.

\section{Result and discussions}

Here, we describe the preparation of the noble metal doped graphene hybrid materials in a simple and scalable route as well as their characterizations using Scanning Electron Microscopy (SEM), Energy-Dispersive X-ray Spectroscopy (EDX), X-ray Photoelectron Spectroscopy (XPS), Inductively Coupled Plasma-Mass Spectroscopy (ICP-MS), Raman spectroscopy and cyclic voltammetry $(\mathrm{CV})$. We then elaborate the electrochemical responses originating from reduction of hydrogen peroxide $\left(\mathrm{H}_{2} \mathrm{O}_{2}\right)$, oxidation of hydrazine $\left(\mathrm{N}_{2} \mathrm{H}_{4}\right)$ and reduction of oxygen $\left(\mathrm{O}_{2}\right)$ dissolved in potassium hydroxide $(\mathrm{KOH})$ solution on the materials.

The noble metal doped-graphene hybrid materials were prepared by dispersing graphite oxide in $1 \%$ solutions of the salts of the metals of interest (palladium(II) chloride, ruthenium(III) chloride, rhodium(III) chloride, ammonium hexachloroplatinate(Iv), gold(III) chloride and silver nitrate). The metal doped graphite oxide precursors were then heated to $1000{ }^{\circ} \mathrm{C}$ under a flow of pure nitrogen or hydrogen gases to exfoliate the materials, resulting in the metal doped graphene hybrid materials. These materials are called $\mathrm{G}-\mathrm{M} / \mathrm{N}_{2}$ and $\mathrm{G}-\mathrm{M} / \mathrm{H}_{2}$ for materials exfoliated in nitrogen and hydrogen atmospheres, respectively, where $\mathrm{M}$ refers to the metal contained within each sample, namely $\mathrm{Pd}, \mathrm{Ru}, \mathrm{Rh}, \mathrm{Pt}, \mathrm{Au}$ or Ag. The different exfoliation atmospheres result in different oxygen-containing group contents on the graphene surfaces, where $\mathrm{G}-\mathrm{M} / \mathrm{H}_{2}$ contains a lower amount of oxygen-containing groups than $\mathrm{G}-\mathrm{M} / \mathrm{N}_{2}$ (ref. 21). Scheme 1 outlines the production of the materials.

Scanning Electron Microscopy (SEM) images of all G-M/N $\mathrm{N}_{2}$ are shown in Fig. 1. All the analyzed materials exhibited similar structures, confirming the successful formation of thermally reduced graphene. Using this technique, however, it was not possible to identify and visualize the metal components.

In order to verify and confirm the presence of the metals in the hybrid materials we adopted several complementary techniques. X-ray Photoelectron Spectroscopy (XPS) and Energy-Dispersive $\mathrm{X}$-ray Spectroscopy (EDX) spectra are shown in Fig. 2. From EDX, the amounts of metal components within G-Pd/N $\mathrm{N}_{2}, \mathrm{G}-\mathrm{Ru} /$ $\mathrm{N}_{2}$ and $\mathrm{G}-\mathrm{Au} / \mathrm{N}_{2}$ were found to be $0.10 \%$ of $\mathrm{Pd}, 0.16 \%$ of $\mathrm{Ru}$ and $0.20 \%$ of $\mathrm{Au}$, respectively, while the XPS spectra of those materials revealed the metal contents to be $0.26 \%$ of $\mathrm{Pd}, 0.50 \%$ of $\mathrm{Ru}$ and $0.05 \%$ of Au. G-Pt/ $\mathrm{H}_{2}$ contained $0.057 \%$ of $\mathrm{Pt}$ and $\mathrm{G}-\mathrm{Au} /$ $\mathrm{H}_{2}$ contained $0.037 \%$ of Au. Other hybrids did not show any

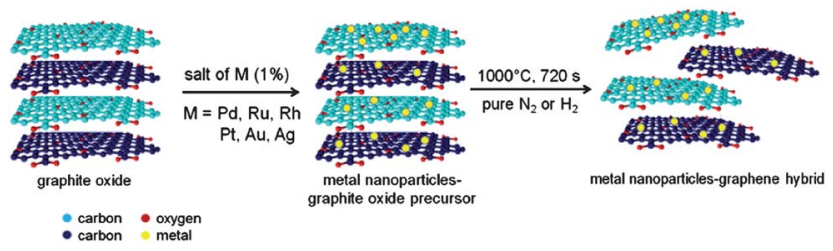

Scheme 1 The production route of noble metal doped-graphene hybrid materials. Hydrogen atoms are not shown.

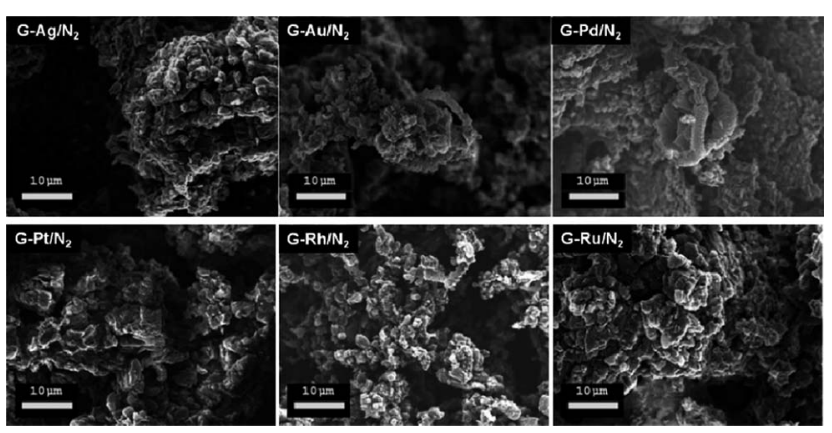

Fig. 1 Scanning Electron Microscopy (SEM) images of G-Pd/ $\mathrm{N}_{2}, \mathrm{G}-\mathrm{Ru} /$ $\mathrm{N}_{2}, \mathrm{G}-\mathrm{Rh} / \mathrm{N}_{2}, \mathrm{G}-\mathrm{Pt} / \mathrm{N}_{2}, \mathrm{G}-\mathrm{Au} / \mathrm{N}_{2}$ and $\mathrm{G}-\mathrm{Ag} / \mathrm{N}_{2}$.
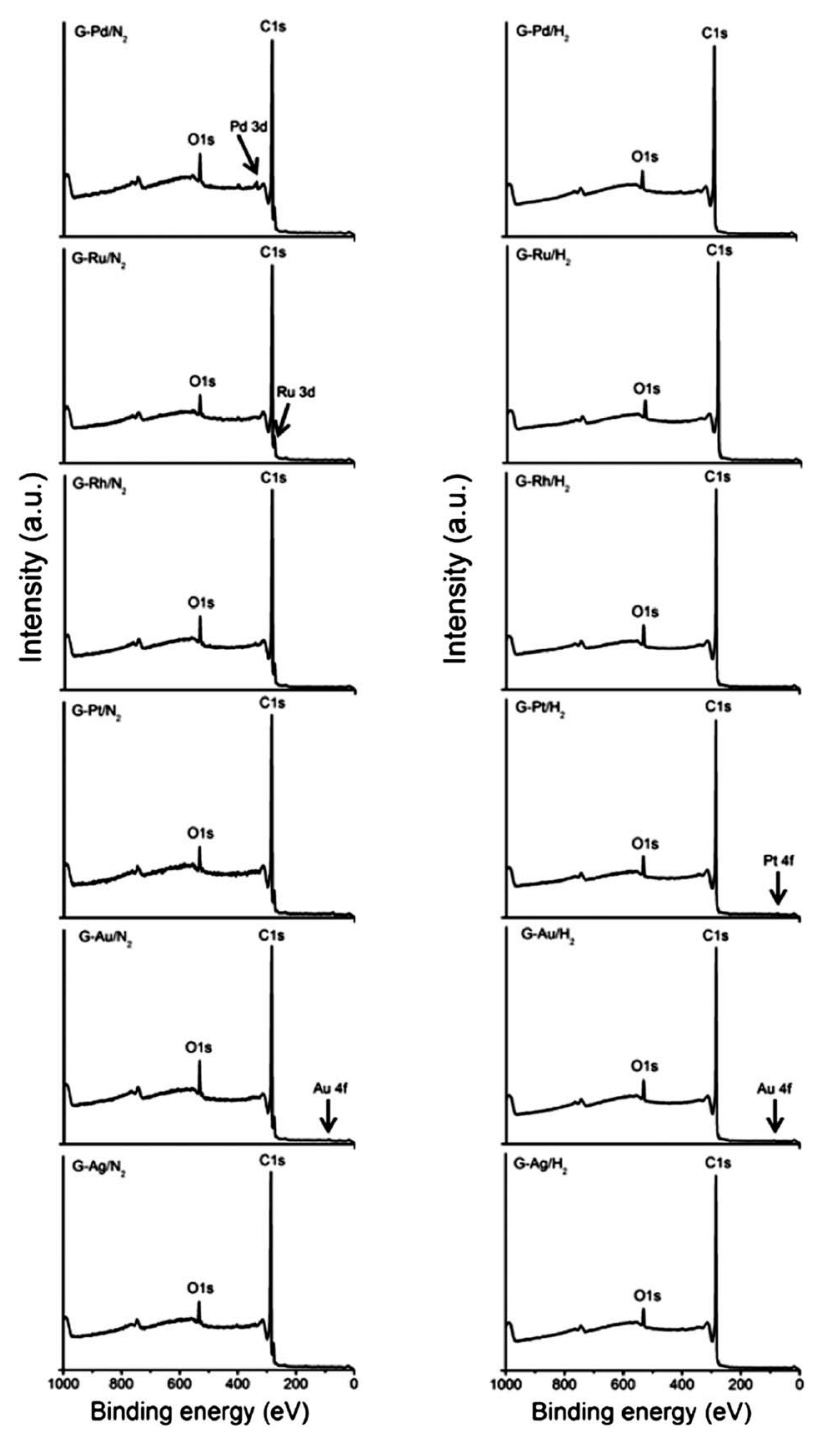

Fig. 2 X-ray Photoelectron Spectroscopy (XPS) wide scan spectra of all materials.

peaks coming from the metals in their EDX and/or XPS wide scan spectra. It should be noted that XPS is a surface-sensitive technique with the maximum depth of analysis in carbon samples of $\sim 10 \mathrm{~nm}$, and that EDX and XPS have detection limits at $\sim 0.1 \%$ of the material, ${ }^{22}$ hence the absence of the metal peaks 
may be caused by the low amounts of the metals present on the surfaces of the materials.

In order to determine the exact amount of the metal components in each material, all hybrids were analyzed by using Inductively Coupled Plasma-Mass Spectrometry (ICPMS). The amount of the metal in each hybrid is expressed as the mass of the metal components (in milligrams) in 1 gram of a sample. The concentrations of the metals are listed in Table 1 .

It is clear that a significant amount of metal is present in the metal-graphene hybrids after the thermal exfoliation/reduction. The XPS high resolution spectra of carbon $(\mathrm{C} 1 \mathrm{~s})$ are presented in Fig. 3. They display the compositions and the functional groups present on the surfaces of the hybrid materials. All G-M/ $\mathrm{N}_{2}$ showed similar $\mathrm{sp}^{2}$ and $\mathrm{sp}^{3}$ carbon as well as $\mathrm{C}-\mathrm{O}$ group contents. Likewise, the compositions of carbons and $\mathrm{C}-\mathrm{O}$ groups among all $\mathrm{G}-\mathrm{M} / \mathrm{H}_{2}$ were also similar.

The presence of oxygen-containing groups on the surface of a graphene material may influence the electrochemical behavior of the material. The amounts of oxygen-containing groups on the surfaces of all the hybrid materials were determined by using XPS wide scan spectra. The carbon to oxygen $(\mathrm{C} / \mathrm{O})$ ratio for each material was calculated based on $\mathrm{C} 1 \mathrm{~s}$ and $\mathrm{O} 1 \mathrm{~s}$ peak intensities extrapolated from the spectra and the values are listed in Table 2. Among all G-M/N $\mathrm{N}_{2}, \mathrm{G}-\mathrm{Au} / \mathrm{N}_{2}$ exhibited the lowest $\mathrm{C} / \mathrm{O}$ ratio of 12.58 and $\mathrm{G}-\mathrm{Ru} / \mathrm{N}_{2}$ had the highest $\mathrm{C} / \mathrm{O}$ ratio of 19.60 , which implies that $\mathrm{G}-\mathrm{Ru} / \mathrm{N}_{2}$ contains less oxygen-containing groups than other materials exfoliated in the same atmosphere. For materials exfoliated in $\mathrm{H}_{2}\left(\mathrm{G}-\mathrm{M} / \mathrm{H}_{2}\right)$, the lowest and highest $\mathrm{C} / \mathrm{O}$ ratios came from $\mathrm{G}-\mathrm{Au} / \mathrm{H}_{2}$ and $\mathrm{G}-\mathrm{Pd} / \mathrm{H}_{2}$ with 18.83 and 23.20, respectively. In general, $\mathrm{G}-\mathrm{M} / \mathrm{H}_{2}$ has higher $\mathrm{C} / \mathrm{O}$ ratio than $\mathrm{G}-\mathrm{M} / \mathrm{N}_{2}$, indicating that the latter contains a higher amount of oxygen-containing groups on the surface. This agrees with the observations reported by other groups. ${ }^{21}$

Fig. 4 shows the Raman spectra of all materials. There are two important bands in all spectra: the G-band at $\sim 1560 \mathrm{~cm}^{-1}$ that corresponds to the $\mathrm{sp}^{2}$ lattice of the graphitic materials and the D-band at $\sim 1350 \mathrm{~cm}^{-1}$ that corresponds to the defects in the $\mathrm{sp}^{2}$ lattice. ${ }^{9}$ The intensity of the D-band reflects the density of defects in the material which may be caused by thermal exfoliation, the presence of oxygen-containing groups ${ }^{9}$ or graphene-metal interactions. ${ }^{12}$ The defects may greatly influence the electrochemical behavior of the materials. The ratios of the intensities of D-bands to G-bands (D/G ratios) of all the materials are presented in Table 2. In general, G-M/ $\mathrm{H}_{2}$ has more defects on the surface than $\mathrm{G}-\mathrm{M} / \mathrm{N}_{2}$.

Table 1 The concentrations (mg of metal per gram of sample) of the metal components in the noble metal doped graphene hybrid materials

\begin{tabular}{lllll}
\hline Element & Material & $\begin{array}{l}\text { Element } \\
\text { concentration } \\
\left(\mathrm{mg} \mathrm{g}^{-1}\right)\end{array}$ & Material & $\begin{array}{l}\text { Element } \\
\text { concentration } \\
\left(\mathrm{mg} \mathrm{g}^{-1}\right)\end{array}$ \\
\hline $\mathrm{Pd}$ & $\mathrm{G}-\mathrm{Pd} / \mathrm{N}_{2}$ & 20.68 & $\mathrm{G}-\mathrm{Pd} / \mathrm{H}_{2}$ & 25.42 \\
$\mathrm{Ru}$ & $\mathrm{G}-\mathrm{Ru} / \mathrm{N}_{2}$ & 13.35 & $\mathrm{G}-\mathrm{Ru} / \mathrm{H}_{2}$ & 14.88 \\
$\mathrm{Rh}$ & $\mathrm{G}-\mathrm{Rh} / \mathrm{N}_{2}$ & 0.39 & $\mathrm{G}-\mathrm{Rh} / \mathrm{H}_{2}$ & 0.17 \\
$\mathrm{Pt}$ & $\mathrm{G}-\mathrm{Pt} / \mathrm{N}_{2}$ & 12.57 & $\mathrm{G}-\mathrm{Pt} / \mathrm{H}_{2}$ & 5.181 \\
$\mathrm{Au}$ & $\mathrm{G}-\mathrm{Au} / \mathrm{N}_{2}$ & 3.027 & $\mathrm{G}-\mathrm{Au} / \mathrm{H}_{2}$ & 1.709 \\
$\mathrm{Ag}$ & $\mathrm{G}-\mathrm{Ag} / \mathrm{N}_{2}$ & 8.944 & $\mathrm{G}-\mathrm{Ag} / \mathrm{H}_{2}$ & 9.625 \\
\hline
\end{tabular}
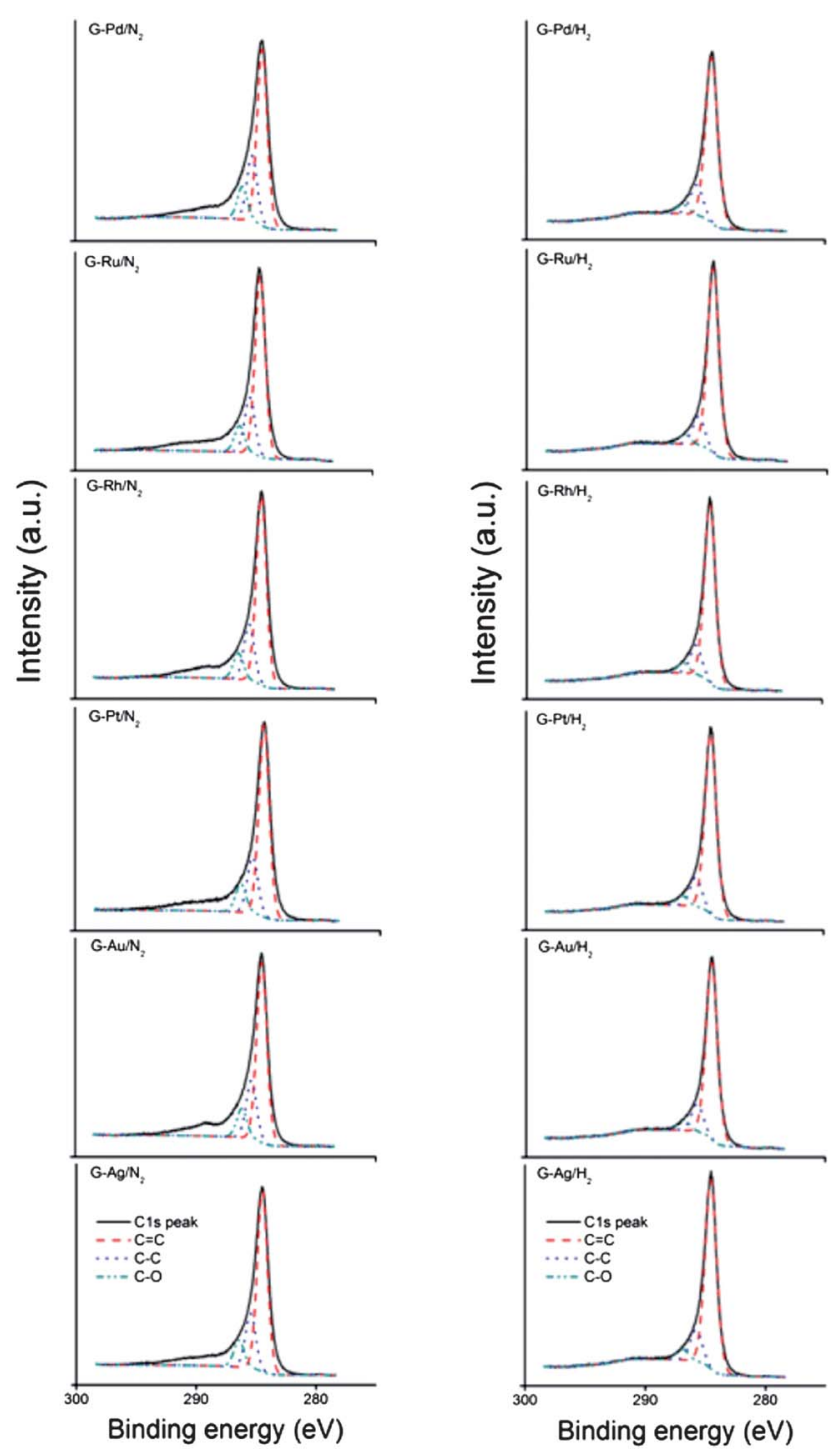

Fig. 3 X-ray Photoelectron Spectroscopy (XPS) high resolution spectra of $\mathrm{C} 1 \mathrm{~s}$ of all materials.

From the Raman spectra, the crystallite size $\left(L_{\mathrm{a}}\right)$ of the $\mathrm{sp}^{2}$ lattice of each hybrid was calculated by using the equation below

$$
L_{\mathrm{a}}=2.4 \times 10^{-10} \times \lambda^{4}{ }_{\text {laser }} \times I_{\mathrm{G}} / I_{\mathrm{D}}
$$

where $\lambda_{\text {laser }}$ is the wavelength of the laser in $\mathrm{nm}(514.5 \mathrm{~nm})$ and $I_{\mathrm{G}}$ and $I_{\mathrm{D}}$ are the intensities of the Raman G-band and D-band, respectively. The sizes of the $\mathrm{sp}^{2}$ lattices of the hybrids are also presented in Table 2.

It is evident that the preparation procedure generates materials with very similar structural conformation resulting in almost equivalent density of defects and crystallite sizes. Following the detailed characterizations of the noble metal doped graphene hybrid materials, the abilities of the hybrids to catalyze reduction/oxidation reactions of compounds which are important for electrochemical sensing and energy production and storage were investigated by cyclic voltammetry $(\mathrm{CV}) . \mathrm{CV}$ is also a powerful technique to study the heterogeneous electron transfer processes occurring on the electrode surface and the nature of interactions 
Table 2 The $\mathrm{C} / \mathrm{O}$ ratios, D/G ratios and crystallite sizes $\left(L_{\mathrm{a}}\right)$ of all materials

\begin{tabular}{llll}
\hline Material & C/O ratio & D/G ratio & $\begin{array}{l}\text { Crystallite size } \\
\left(L_{\mathrm{a}}, \text { in } \mathrm{nm}\right)\end{array}$ \\
\hline $\mathrm{G}-\mathrm{Pd} / \mathrm{N}_{2}$ & 14.69 & 0.883 & 19 \\
$\mathrm{G}-\mathrm{Ru} / \mathrm{N}_{2}$ & 19.60 & 0.960 & 18 \\
$\mathrm{G}-\mathrm{Rh} / \mathrm{N}_{2}$ & 15.16 & 1.026 & 16 \\
$\mathrm{G}-\mathrm{Pt} / \mathrm{N}_{2}$ & 14.82 & 0.949 & 18 \\
$\mathrm{G}-\mathrm{Au} / \mathrm{N}_{2}$ & 12.58 & 1.018 & 16 \\
$\mathrm{G}-\mathrm{Ag} / \mathrm{N}_{2}$ & 17.29 & 0.920 & 18 \\
$\mathrm{G}-\mathrm{Pd} / \mathrm{H}_{2}$ & 23.20 & 0.959 & 18 \\
$\mathrm{G}-\mathrm{Ru} / \mathrm{H}_{2}$ & 22.00 & 1.105 & 15 \\
$\mathrm{G}-\mathrm{Rh} / \mathrm{H}_{2}$ & 19.30 & 1.180 & 14 \\
$\mathrm{G}-\mathrm{Pt} / \mathrm{H}_{2}$ & 22.73 & 1.086 & 15 \\
$\mathrm{G}-\mathrm{Au} / \mathrm{H}_{2}$ & 18.83 & 1.107 & 15 \\
$\mathrm{G}-\mathrm{Ag} / \mathrm{H}_{2}$ & 22.76 & 1.054 & 16 \\
\hline
\end{tabular}
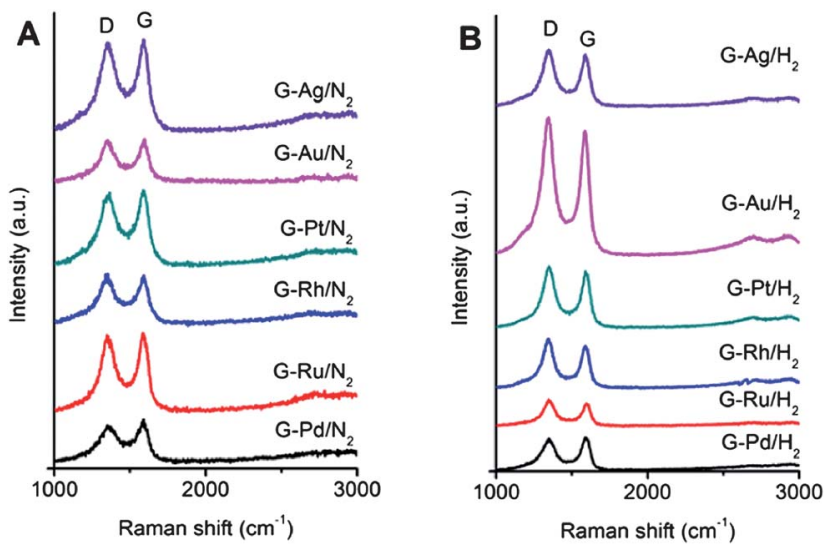

Fig. 4 Raman spectra of the noble metal doped graphene hybrid materials exfoliated in (A) nitrogen atmosphere and (B) hydrogen atmosphere.

between molecules and the electrode surface. ${ }^{9}$ Cyclic voltammograms of several compounds on the hybrid materials were recorded and thermally reduced graphene materials without any metal components (denoted as $\mathrm{G} / \mathrm{N}_{2}$ and $\mathrm{G} / \mathrm{H}_{2}$ ) were used as control materials. The effects of the exfoliation atmospheres and the presence of the metals on the electrochemical behavior and catalytic activities of the materials were examined. To evaluate the kinetics of electron transfer on the noble metal doped graphene hybrid surfaces, CV experiments were performed in a $50 \mathrm{mM}$ phosphate buffer solution ( $\mathrm{pH}$ 7.2) containing $10 \mathrm{mM}$ of potassium hexacyanoferrate(II) and potassium hexacyanoferrate(III) $\left(\left[\mathrm{Fe}(\mathrm{CN})_{6}\right]^{3-14-}\right.$ redox couple) in $1: 1$ molar ratio. The resulting voltammograms are plotted in Fig. 5. Among all the materials exfoliated in $\mathrm{N}_{2}$ atmosphere $\left(\mathrm{G}-\mathrm{M} / \mathrm{N}_{2}\right), \mathrm{G}-\mathrm{Rh} /$ $\mathrm{N}_{2}$ exhibited the lowest peak-to-peak separation $\left(\Delta E_{\mathrm{p}}\right)$ of $134 \mathrm{mV}$, corresponding to heterogeneous electron transfer rate $\left(k^{0}{ }_{\text {obs }}\right)$ of $2.72 \times 10^{-3} \mathrm{~cm} \mathrm{~s}^{-1}$. G-Pd/N $\mathrm{N}_{2}$ and $\mathrm{G}-\mathrm{Ag} / \mathrm{N}_{2}$ also had low $\Delta E_{\mathrm{p}}$ of $135 \mathrm{mV}\left(k_{\text {obs }}^{0}=2.68 \times 10^{-3} \mathrm{~cm} \mathrm{~s}^{-1}\right)$. This value is smaller by $17 \mathrm{mV}$ compared to the $\Delta E_{\mathrm{p}}$ observed on $\mathrm{G} / \mathrm{N}_{2}$ as the control material for materials exfoliated in $\mathrm{N}_{2}$. The control material for materials exfoliated in $\mathrm{H}_{2}, \mathrm{G} / \mathrm{H}_{2}$, had a large $\Delta E_{\mathrm{p}}$ of $319 \mathrm{mV}$ $\left(k_{\text {obs }}^{0}=2.53 \times 10^{-4} \mathrm{~cm} \mathrm{~s}^{-1}\right)$, and among all the materials exfoliated in $\mathrm{H}_{2}$ atmosphere $\left(\mathrm{G}-\mathrm{M} / \mathrm{H}_{2}\right), \mathrm{G}-\mathrm{Ag} / \mathrm{H}_{2}$ presented the
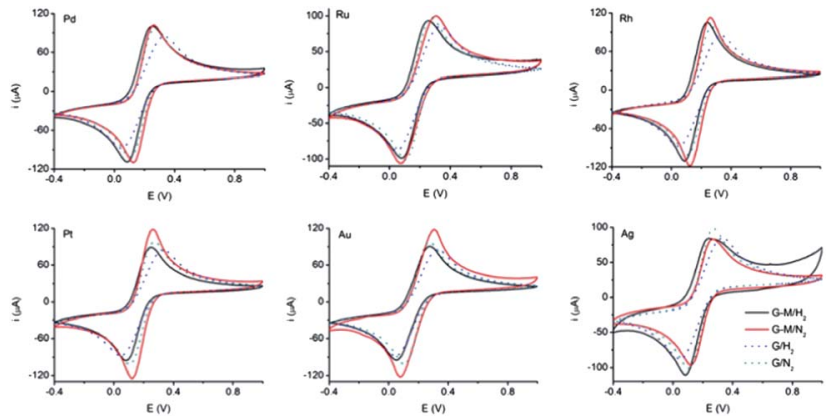

Fig. 5 Cyclic voltammograms of $\mathrm{K}_{4}\left[\mathrm{Fe}(\mathrm{CN})_{6}\right] / \mathrm{K}_{3}\left[\mathrm{Fe}(\mathrm{CN})_{6}\right](10 \mathrm{mM}$, $1: 1$ molar ratio) on the noble metal doped graphene hybrid materials. Graphene materials that do not contain metals were used as control materials. Scan rate: $100 \mathrm{mV} \mathrm{s}^{-1}$, buffer: phosphate buffer solution (50 mM, pH 7.2).

lowest $\Delta E_{\mathrm{p}}$ at $144 \mathrm{mV}$ and therefore the fastest electron transfer with $k_{\text {obs }}^{0}=2.38 \times 10^{-3} \mathrm{~cm} \mathrm{~s}^{-1}$, followed by G-Rh/ $\mathrm{H}_{2}\left(\Delta E_{\mathrm{p}}=\right.$ $\left.149 \mathrm{mV}, k^{0}{ }_{\text {obs }}=2.22 \times 10^{-3} \mathrm{~cm} \mathrm{~s}^{-1}\right)$ and G-Pd/H $/ \mathrm{H}_{2}\left(\Delta E_{\mathrm{p}}=\right.$ $\left.156 \mathrm{mV}, k_{\text {obs }}^{0}=2.02 \times 10^{-3} \mathrm{~cm} \mathrm{~s}^{-1}\right)$. In general, G-M/H 2 exhibits bigger $\Delta E_{\mathrm{p}}$ values, slower heterogeneous electron transfer and smaller peak currents than G-M/N $\mathrm{N}_{2}$. Materials with more oxygen-containing groups (i.e. smaller $\mathrm{C} / \mathrm{O}$ ratio) were found to have slower electron transfer and bigger $\Delta E_{\mathrm{p}}$ due to charge repulsions between the negatively charged $\left[\mathrm{Fe}(\mathrm{CN})_{6}\right]^{3-/ 4-}$ redox probe and the oxygen-containing groups which have negative charges at the working $\mathrm{pH} .{ }^{9}$ That, however, is not the case here. Rather, the metals, specifically $\mathrm{Pd}, \mathrm{Rh}$ and $\mathrm{Ag}$, act as electrocatalysts and influence the electron transfer for redox reaction of $\left[\mathrm{Fe}(\mathrm{CN})_{6}\right]^{3-/ 4-}$ regardless of the atmosphere in which the hybrid materials underwent the exfoliation, thus dominating the electrochemistry of their respective hybrid material (Table 3).

The abilities of the metal nanoparticles on the graphene sheets to act as the catalysts for electrochemical reactions were then observed for (1) reduction of hydrogen peroxide $\left(\mathrm{H}_{2} \mathrm{O}_{2}\right)$, a strong oxidizing agent; (2) oxidation of hydrazine $\left(\mathrm{N}_{2} \mathrm{H}_{4}\right)$, a reducing agent; and (3) reduction of oxygen $\left(\mathrm{O}_{2}\right)$ dissolved in potassium hydroxide $(\mathrm{KOH})$ which is important for energy production and storage. The voltammograms are shown in Fig. $6\left(\mathrm{H}_{2} \mathrm{O}_{2}\right)$, Fig. 7 $\left(\mathrm{N}_{2} \mathrm{H}_{4}\right)$ and Fig. $8\left(\mathrm{O}_{2}\right.$ dissolved in $\left.\mathrm{KOH}\right)$.

The reduction peaks of $\mathrm{H}_{2} \mathrm{O}_{2}$ on G-Pt/ $\mathrm{N}_{2}$ and G-Pd/ $\mathrm{N}_{2}$ started earliest at $+50 \mathrm{mV}$ compared to the other materials exfoliated in $\mathrm{N}_{2}\left(\mathrm{G}-\mathrm{M} / \mathrm{N}_{2}\right)$ and they reached maximum at $-532 \mathrm{mV}\left(\mathrm{G}-\mathrm{Pt} / \mathrm{N}_{2}\right)$ and $-510 \mathrm{mV}\left(\mathrm{G}-\mathrm{Pd} / \mathrm{N}_{2}\right)$. G-Au/ $\mathrm{N}_{2}$ and G-Ru/ $\mathrm{N}_{2}$ achieved the earliest maximum reduction peak potential among all the G-M/ $\mathrm{N}_{2}$ with $-448 \mathrm{mV}$. The maximum reduction peak potential of $\mathrm{G}-\mathrm{Au} / \mathrm{H}_{2}$ was $-438 \mathrm{mV}$, the earliest among all materials exfoliated in $\mathrm{H}_{2}\left(\mathrm{G}-\mathrm{M} / \mathrm{H}_{2}\right)$. The control materials, which were graphenes that do not contain any metals, $\mathrm{G} / \mathrm{N}_{2}$ and $\mathrm{G} / \mathrm{H}_{2}$, had maximum reduction peak potential values of -892 and $-784 \mathrm{mV}$, respectively. This clearly demonstrates the electrocatalytic reduction of $\mathrm{H}_{2} \mathrm{O}_{2}$ on the surface of the metal nanoparticles dispersed on graphene sheets.

On the platinum-graphene hybrids $\left(\mathrm{G}-\mathrm{Pt} / \mathrm{N}_{2}\right.$ and $\left.\mathrm{G}-\mathrm{Pt} / \mathrm{H}_{2}\right)$, the oxidation peaks for $\mathrm{N}_{2} \mathrm{H}_{4}$ started early at $0 \mathrm{~V}$; however, the maximum potentials were reached at high potentials of $+651 \mathrm{mV}$ and $+611 \mathrm{mV}$ for G-Pt/ $\mathrm{N}_{2}$ and G-Pt/ $\mathrm{H}_{2}$, respectively. G- $\mathrm{Rh} / \mathrm{N}_{2}$ showed an oxidation peak that reached a maximum at $+549 \mathrm{mV}$, 
Table 3 Peak-to-peak separation $\left(\Delta E_{\mathrm{p}}\right)$ values and the corresponding heterogeneous electron transfer rates $\left(k_{0}{ }^{\text {obs }}\right)$ of the $\left[\mathrm{Fe}(\mathrm{CN})_{6}\right]^{3-/ 4-}$ redox couple on all materials

\begin{tabular}{lll}
\hline Material & $\Delta E_{\mathrm{p}}(\mathrm{mV})$ & $k_{0}{ }^{\text {obs }}\left(\mathrm{cm} \mathrm{s}^{-1}\right)$ \\
\hline $\mathrm{G}-\mathrm{Pd} / \mathrm{N}_{2}$ & 135 & $2.68 \times 10^{-3}$ \\
$\mathrm{G}-\mathrm{Ru} / \mathrm{N}_{2}$ & 268 & $4.41 \times 10^{-4}$ \\
$\mathrm{G}-\mathrm{Rh} / \mathrm{N}_{2}$ & 134 & $2.72 \times 10^{-3}$ \\
$\mathrm{G}-\mathrm{Pt} / \mathrm{N}_{2}$ & 154 & $2.07 \times 10^{-3}$ \\
$\mathrm{G}-\mathrm{Au} / \mathrm{N}_{2}$ & 180 & $1.46 \times 10^{-3}$ \\
$\mathrm{G}-\mathrm{Ag} / \mathrm{N}_{2}$ & 135 & $2.68 \times 10^{-3}$ \\
$\mathrm{G} / \mathrm{N}_{2}$ & 152 & $2.13 \times 10^{-3}$ \\
$\mathrm{G}-\mathrm{Pd} / \mathrm{H}_{2}$ & 156 & $2.02 \times 10^{-3}$ \\
$\mathrm{G}-\mathrm{Ru} / \mathrm{H}_{2}$ & 164 & $1.81 \times 10^{-3}$ \\
$\mathrm{G}-\mathrm{Rh} / \mathrm{H}_{2}$ & 149 & $2.22 \times 10^{-3}$ \\
$\mathrm{G}-\mathrm{Pt} / \mathrm{H}_{2}$ & 161 & $1.89 \times 10^{-3}$ \\
$\mathrm{G}-\mathrm{Au} / \mathrm{H}_{2}$ & 252 & $5.48 \times 10^{-4}$ \\
$\mathrm{G}-\mathrm{Ag} / \mathrm{H}_{2}$ & 144 & $2.38 \times 10^{-3}$ \\
$\mathrm{G} / \mathrm{H}_{2}$ & 309 & $2.53 \times 10^{-4}$ \\
\hline
\end{tabular}
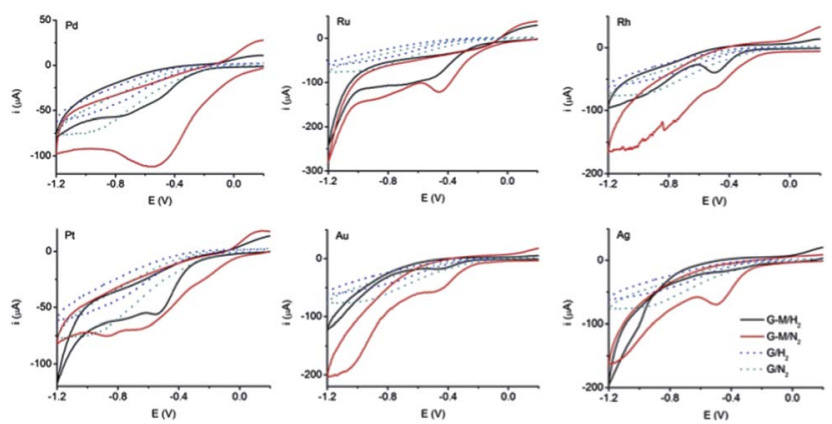

Fig. 6 Cyclic voltammograms of the reduction of hydrogen peroxide $(10 \mathrm{mM})$ on the noble metal doped graphene hybrid materials. Graphene materials that do not contain metals were used as control materials. Scan rate: $100 \mathrm{mV} \mathrm{s}^{-1}$, buffer: phosphate buffer solution (50 mM, pH 7.2).
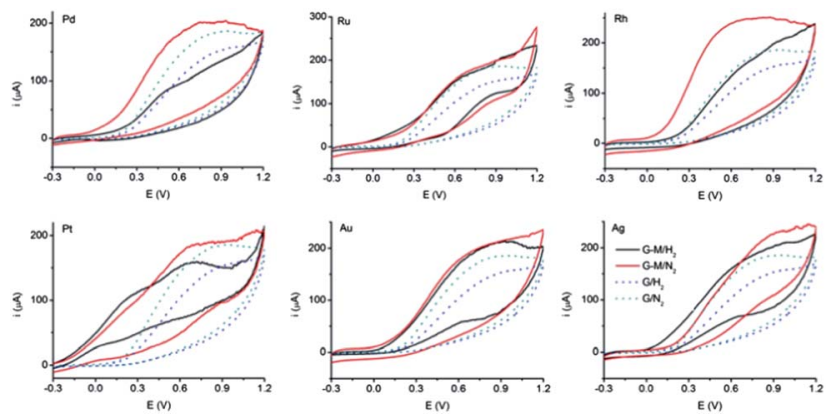

Fig. 7 Cyclic voltammograms of the oxidation of hydrazine $(10 \mathrm{mM})$ on the noble metal doped graphene hybrid materials. Graphene materials that do not contain metals were used as control materials. Scan rate: $100 \mathrm{mV} \mathrm{s}^{-1}$, buffer: phosphate buffer solution (50 mM, pH 7.2).

the lowest among all G-M/ $\mathrm{N}_{2}$, while $\mathrm{G}-\mathrm{Pd} / \mathrm{H}_{2}$ presented the earliest maximum oxidation peak potential among all G-M/ $\mathrm{H}_{2}$ at $+504 \mathrm{mV}$. The oxidation peaks recorded on $\mathrm{G} / \mathrm{N}_{2}$ and $\mathrm{G} / \mathrm{H}_{2}$ achieved maximum at $+706 \mathrm{mV}$ and $+728 \mathrm{mV}$, respectively. The results suggest that the metals on the surfaces of the graphene sheets influence the catalysis of the oxidation reaction.
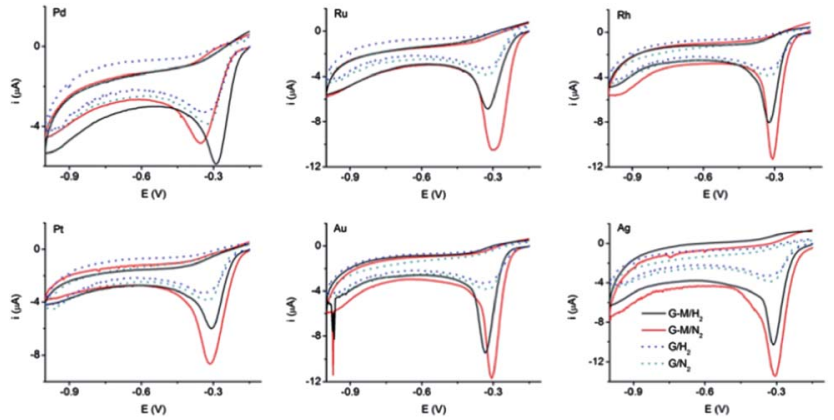

Fig. 8 Cyclic voltammograms of the reduction of oxygen dissolved in potassium hydroxide ( $2 \mathrm{M}, \mathrm{pH} 13.85$ ) on the noble metal doped graphene hybrid materials. Graphene materials that do not contain metals were used as control materials. Scan rate: $10 \mathrm{mV} \mathrm{s}^{-1}$.

For oxygen reduction reaction in $2 \mathrm{M} \mathrm{KOH} \mathrm{(pH} \mathrm{13.85),} \mathrm{G-Pt/}$ $\mathrm{H}_{2}$ gave the reduction peak potential at $-301 \mathrm{mV}$, the earliest among the materials exfoliated in the same atmosphere. The maximum reduction peak from G-Pt/ $\mathrm{N}_{2}$ appeared at $-310 \mathrm{mV}$, which was higher than the other materials exfoliated in $\mathrm{N}_{2}$ atmosphere. The reduction peak from G-Pd/ $\mathrm{N}_{2}$ was reached at $-288 \mathrm{mV}$, the earliest among all G-M/N $\mathrm{N}_{2}$. It should be taken into account that oxygen reduction reactions are usually facilitated by platinum-based catalysts. ${ }^{17}$ The peaks from the two control materials reached maximum at $-321 \mathrm{mV}\left(\mathrm{G} / \mathrm{H}_{2}\right)$ and $-315 \mathrm{mV}\left(\mathrm{G} / \mathrm{N}_{2}\right)$, giving $20-27 \mathrm{mV}$ differences between the peak potentials of the control and metal doped graphene hybrid materials. The reduction currents originating from all metal doped graphene hybrid materials were also greatly enhanced compared to those from the control materials; therefore the metals possess good catalytic activities for oxygen reduction reactions. The results obtained in this experiment are comparable with the results published by other groups. ${ }^{23}$

\section{Conclusions}

Graphene and metal nanoparticles are of great interest and importance in electrochemical analysis due to their distinctive properties. Noble metal doped graphene hybrid materials exfoliated in nitrogen and hydrogen atmospheres were synthesized here in a simple and scalable route. The characterizations of the materials suggest that the atmospheres in which the materials are exfoliated have a strong influence on the amount of oxygencontaining groups as well as the density of defects on the surface of the hybrid materials, with materials exfoliated in $\mathrm{N}_{2}$ containing more oxygen-containing groups and having a lower density of defects than those exfoliated in $\mathrm{H}_{2}$. The noble metal nanoparticles supported on graphene materials were able to enhance the heterogeneous electron transfer rate and catalyze reduction and oxidation reactions of hydrogen peroxide, hydrazine and oxygen in alkaline media, therefore bringing a broad range of possible applications of these materials in energy production and storage, electrochemical sensing and biosensing as well as electrocatalysis. Further research could be done to assess the effects of other exfoliation/reduction methods as well as the performances of other metals, such as base metals, supported on graphene materials for similar applications. 


\section{Acknowledgements}

M.P. acknowledges the funding support for this project from Nanyang Technological University (NAP programme). Z.S. and F.S. were supported by the Ministry of Education of the Czech Republic (research project no. MSM6046137302) and by "Specific university research" (MSMT no. 21/2012).

\section{References}

1 M. J. Allen, V. C. Tung and R. B. Kaner, Chem. Rev., 2009, 110, 132145.

2 M. Pumera, Energy Environ. Sci., 2011, 4, 668-674.

3 X. Wang, L. Zhi and K. Mullen, Nano Lett., 2007, 8, 323-327.

4 C. Huang, H. Bai, C. Li and G. Shi, Chem. Commun., 2011, 47, 49624964.

5 H. S. Toh, A. Ambrosi, C. K. Chua and M. Pumera, J. Phys. Chem. C, 2011, 115, 17647-17650.

6 A. Bonanni and M. Pumera, ACS Nano, 2011, 5, 2356-2361.

7 M. Giovanni, A. Bonanni and M. Pumera, Analyst, 2012, 137, 580583.

8 D. R. Dreyer, R. S. Ruoff and C. W. Bielawski, Angew. Chem., Int. Ed., 2010, 49, 9336-9344.

9 A. Ambrosi, A. Bonanni, Z. Sofer, J. S. Cross and M. Pumera, Chem.-Eur. J., 2011, 17, 10763-10770.
10 C. Welch and R. Compton, Anal. Bioanal. Chem., 2006, 384, 601-619.

11 X. Luo, A. Morrin, A. J. Killard and M. R. Smyth, Electroanalysis, 2006, 18, 319-326.

12 A. Gutes, B. Hsia, A. Sussman, W. Mickelson, A. Zettl, C. Carraro and R. Maboudian, Nanoscale, 2012, 4, 438-440.

13 Y. Li, X. Fan, J. Qi, J. Ji, S. Wang, G. Zhang and F. Zhang, Nano Res., 2010, 3, 429-437.

14 S. Vadahanambi, J.-H. Jung and I.-K. Oh, Carbon, 2011, 49, 44494457.

15 X.-W. Liu, J.-J. Mao, P.-D. Liu and X.-W. Wei, Carbon, 2011, 49, 477-483.

16 P. V. Kamat, J. Phys. Chem. Lett., 2009, 1, 520-527.

17 A. Morozan, B. Jousselme and S. Palacin, Energy Environ. Sci., 2011, 4, 1238-1254.

18 U. Hofmann and E. König, Z. Anorg. Allg. Chem., 1937, 234, 311336

19 R. S. Nicholson, Anal. Chem., 1965, 37, 1351-1355.

20 D. R. Lide, CRC Handbook of Chemistry and Physics, CRC Press, 1998

21 D. Yang, A. Velamakanni, G. Bozoklu, S. Park, M. Stoller, R. D. Piner, S. Stankovich, I. Jung, D. A. Field, C. A. Ventrice Jr and R. S. Ruoff, Carbon, 2009, 47, 145-152.

22 T. Kolodiazhnyi and M. Pumera, Small, 2008, 4, 1476-1484.

23 Y. Liang, H. Wang, J. Zhou, Y. Li, J. Wang, T. Regier and H. Dai, J. Am. Chem. Soc., 2012, 134, 3517-3523.

24 A. J. Bard, L. R. Faulkner, Electrochemical Methods: Fundamentals and Applications, Wiley, 2nd edn, 2000, p. 571. 